\title{
Correction to: Early postoperative compilations of bone filling in curettage defects
}

\author{
Clark J. Chen ${ }^{1 *}$ and Earl W. Brien ${ }^{2}$
}

Correction to: J Orthop Surg Res (2019) 14: 261

https://doi.org/10.1186/s13018-019-1297-4

In the original publication of this article [1], there was a mistake in Fig. 2. Figure 2a and c should be swapped. The revised Fig. 2 is shown below.

The authors sincerely apologize for the inconvenience caused to the readers.

\section{Author details}

'Miller School of Medicine, University of Miami, Miami, FL 33136, USA.

${ }^{2}$ Department of Orthopaedic Surgery, Cedars Sinai Medical Center, Los

Angeles, CA 90048, USA.

Published online: 28 October 2019

\section{Reference}

1. Chen CJ, Brien EW. Early postoperative compilations of bone filling in curettage defects. J Orthop Surg Res. 2019;14:261. https://doi.org/10.1186/ s13018-019-1297-4.

* Correspondence: cjc217@med.miami.edu

The original article can be found online at https://doi.org/10.1186/s13018019-1297-4

${ }^{1}$ Miller School of Medicine, University of Miami, Miami, FL 33136, USA

Full list of author information is available at the end of the article 


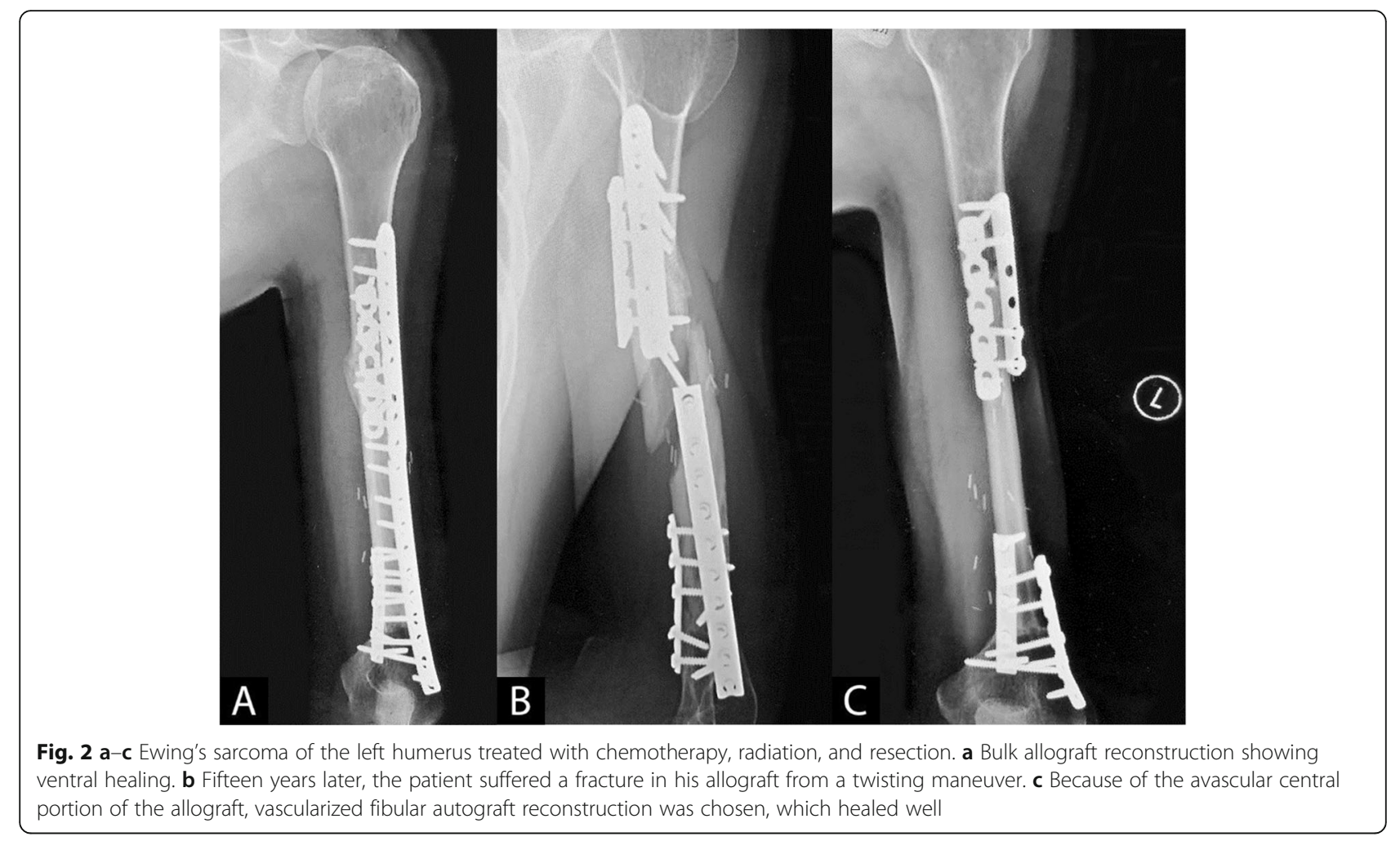

